\title{
Rancang Bangun Running Text pada Dot Matrix 16X160 Berbasis Arduino Uno Dengan Update Data System Menggunakan Perangkat Android Via Bluetooth
}

\author{
Abd Wahid A. Antu \\ Prodi Teknik Elektro \\ Universitas Negeri Gorontalo \\ Gorontalo, Indonesia \\ abdulwahidantu@gmail.com
}

\author{
Syahrir Abdussamad \\ Prodi Teknik Elektro \\ Universitas Negeri Gorontalo \\ Gorontalo, Indonesia \\ syahrirabdussamad@yahoo.co.id
}

\author{
Iskandar Z. Nasibu \\ Prodi Teknik Elektro \\ Universitas Negeri Gorontalo \\ Gorontalo, Indonesia \\ zul.nasibu@ung.ac.id
}

\begin{abstract}
Abstrak-Tujuan dari penelitian ini yaitu, merancang aplikasi android update data running text pada panel LED Matrix p10 melalui perangkat smartphone dengan aplikasi via bluetooth dengan metode experimen. Tahapan pembuatan alat menggunakan bluetooth HC05, sensor suhu (DHT11) untuk ditampilkan pada papan informasi display, RTC (real time clock) 3231 sebagai pembaca waktu untuk menampilkan jam, hari, tanggal, dan panel LED p10 16x60 untuk menampilkan running text. Kemudian untuk pembuatan aplikasi android menggunakan perangkat lunak App Inventor, dimana aplikasi pengontrolan running text diberi nama running text controller (RTC).
\end{abstract}

Hasil penelitian ini adalah aplikasi android dengan pengontrolan bluetooth, dinilai dapat meningkatkan kecepatan dan efisiensi saat penggantian text pada papan display LED matrix 16x160. Rata-rata kecepatan penggantian text bisa dicapai 1,0 detik secara real time dengan jarak $<15$ meter, dan mampu menampung maksimal 255 karakter.

Kata kunci: Aplikasi Androit, Bluetooth, LED matrix 16x160, papan informasi.

\section{PENDAHULUAN}

Perkembangan teknologi yang begitu pesat, memunculkan berbagai inovasi dalam media elektronik salah satunya adalah running text. Selama ini running text digunakan untuk menampilkan informasi yang biasanya digunakan pada minimarket, hotel, gedung pernikahan dan lampu lalu lintas. dimana running text tersebut mengandalkan unit komputer yang masih menggunakan kabel untuk mengirim data running text, yang tentu harganya yang lebih mahal dibandingkan dengan mengguna kan jaringan nirkabel.

Seiring dengan kemajuan dalam bidang teknologi jaringan nirkabel yang saat ini berkembang pesat, dari berbagai macam pengontrolan seperti menggunakan infra red, dimana jaringan nirkabel infrared ini tidak sulit dalam konfigurasinya, proses transfer file yang mudah karena tidak perlu memerlukan sinyal dalan proses transmisinya, dan sangat praktis dipakai dalam transfer data yang berkapasitas kecil baik untuk update data system pada panel LED dot matrix. Akan tetapi penggunaan infrared masih begitu kurang efisien, karena jarak transfer yang relatif dekat (tidak dapat dilakukan pada jarak yang cukup jauh), posisi transfer harus tegak lurus, jika sedikit keluar dari drajat lurus maka koneksi aka hilang (putus), transfer data relatif lama dan keamanan data saat proses transfer sangat kurang.

Bluetooth yang merupakan teknologi yang memungkinkan dua perangkat saling terhubung, dimana memiliki fitur-fitur keamanan enkripsi data, autentikasi user, fast frekuensi-hopping (1600 hops/sec), output power control yang menyediakan fungsi-fungsi keamanan dari tingkat keamanan layer fisik/ radio yaitu gangguan dari penyadapan sampai dengan tingkat keamanan layer yang lebih tinggi seperti password dan PIN dan konsumsi daya yang tidak terlalu tinggi.

Dari permasalah ini maka, bagaimana suatu informasi dapat ditampilkan dalam suatu sistem pengontrolan runing text Dot Matrix P10 16x160 menggunakan jaringan nirkabel yaitu bluetooth melalui perangkat android yang bisa diupdate kapan saja. Sehingga tujuan penelitian ini adalah bagaimana merealisasikan rancangan pengontrolan runing text Dot Matrix P10 16x160 berbasis arduino uno dengan update data system menggunakan perangkat android via bluetooth.

\section{LANDASAN TEORI}

\section{A. Arduino Uno}

Arduino Uno merupakan papan elektronik yang biasa digunakan untuk pengontrolan berupa modul sensor dan 
sejenisnya yang mengandung mikrokontroler Atmega328 (sebuah keping yang secara fungsional bertindak seperti sebuah komputer). Banyak lahir perangkat-perangkat sejenis Arduino, seperti DFRDuino atau Freeduino, dan kalau yang lokal ada namanya CipaDuino yang dibuat oleh SKIR70, terus ada MurmerDuino yang dibuat oleh Robot Unyil, ada lagi AViShaDuino yang salah satu pembuatnya adalah admin kelas robot. Arduino uno sendiri menggunakan mikrokontroller Atmega328. Board ini memiliki 14 pin digital input/output dimana

- 6 pin dapat digunakan sebagai output PWM

- 6 input analog

- $16 \mathrm{MHz}$ osilator kristal

- Port USB

- Jack power

Pin-pin ini berfungsi untuk mendukung mikrokontroller dan hanya terhubung dengan komputer menggunakan kabel usb atau sumber tegangan 5 volt bentuk fisik arduino uno diperlihatkan pada gambar 1.

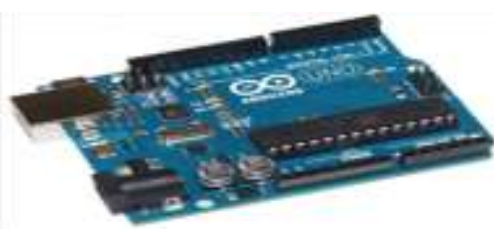

Gambar 1 Arduino Uno

\section{B. Modul Bluetooth}

Modul Bluetooth adalah converter komunikasi serial level TTL (UART) dalam bentuk komunikasi wireless. Modul bluetooth terbagi dua jenis yaitu Modul Bluetooth HC-05 dan HC-06 yang dapat dikontrol mode kerjanya dengan menggunakan standar ATCommand. Level tegangan dari komunikasi serial dari Bluetooth HC-05 \& HC-06 adalah 0 dan 3.3 volt High $=3.3$ Volt dan Low $=0$ Volt. Ini berbeda dengan level tegangan dari komunikasi serial di mikrokontroler. Jadi untuk mengirim data dari mikrokontroler ke Modul Bluetooth lewat komunikasi serial diperlukan voltage devider yaitu R1 dan R2 sehingga sesuai dengan level tegangan dari komunikasi serial di Modul Bluetooth. Sedangkan untuk Transmit data dari modul Bluetooth ke mikrokontroler tidak lagi memerlukan voltage devider, karena level 3.3 Volt dari Modul Bluetooth sudah dianggap Level High oleh mikrokontroler sedangkan Level Low dari Modul bluetooth tetap di angka 0 Volt seperti terlihat pada Gambar 2 yaitu modul bluetooth HC-05 dan HC-06

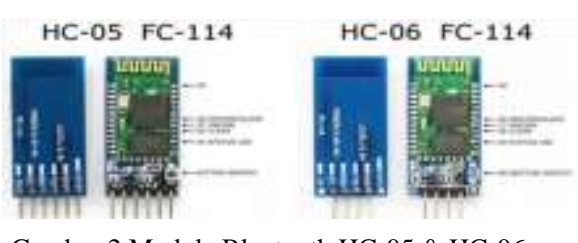

Gambar 2 Module Bluetooth HC-05 \& HC-06

\section{Real Time Clock (RTC)}

RTC adalah modul penghitung waktu dan penyimpan data waktu, dengan adanya komponen ini unit pengendali dapat melakukan pengendalian kerja sistem dengan waktu yang akurat. RTC memiliki kemampuan untuk menghitung waktu dengan tepat. Keunggulan-keunggulan yang dimiliki oleh RTC yaitu diantaranya :

1. Menghitung waktu mulai detik, menit, jam, tanggal, bulan, tahun, hari dalam minggu dengan kompensasi tahun kabisat sampai tahun 2100.

2. Kemampuan untuk selalu membaharui informasi waktu meskipun sumber utama terputus. Berikut merupakan RTC seperti yang terlihat pada Gambar 3.

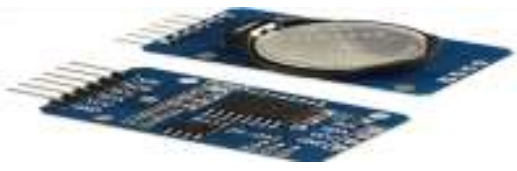

Gambar 3 Real Time Clock

\section{Led Dot Matrix P10 16x32}

P10 LED Matrix merupakan salah satu dari jenis LED Matrix yang ada di pasaran dengan seri P10. Perbedaan pada seri ini adalah sudah dilengkapi dengan register yang sudah tersusun di dalamnya. Dalam kasus penyambungan, seri ini dapat di sambungkan dengan perantara kabel data yang berada di konektor yang sudah terpasang pada LED Matrixnya, berikut gambar 4 LED p10 dot matrix.

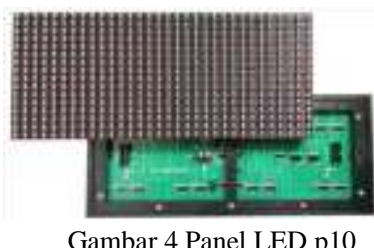

Papan informasi running text ini dilengkapi dengan pembaca sensor suhu dan jam digital, yang akan diolah oleh mikrokontroller arduino uno. Secara keseluruhan sistem dapat dilihat pada Gambar 5

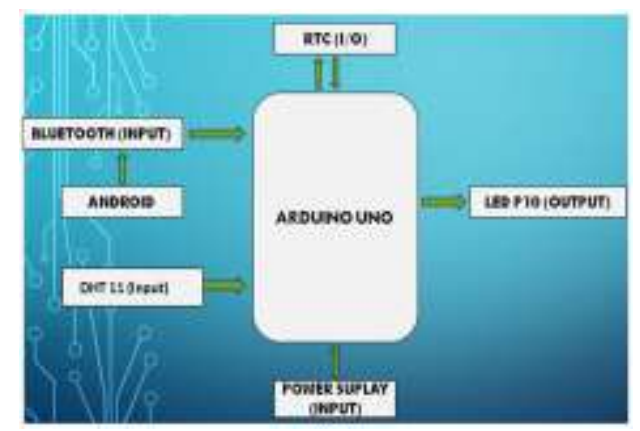

Gambar 5 Digram blok pengontrol running text

\section{METODE}

Metode yang digunakan yaitu metode experimen dimana peneliti melakukan percobaan berulang-ulang untuk mendapatkan hasil yang diinginknan. Rancangan alat ini bekerja dengan mengubah data running text pada panel led matrix yang akan dikontrol melalui aplikasi android dengan koneksi bluetooth. Metode lain yang digunakan adalah dengan perancangan perangkat keras meliputi pengujian masing-masing komponen yang akan digunakan mulai dari Bluetooth HC-05, Arduino Uno, Modul DMD p10, modul RTC 3231, dan modul DHT 11. Serta perangkat lunak yang 
dimaksud adalah program yang akan dimasukkan pada Arduino uno melalui komputer. Program dibuat dengan bahasa $\mathrm{C}$ melalui software Arduino IDE (integrated development environment) dan App Inventor.

\section{HASIL DAN PEMBAHASAN}

\section{A. Hasil Rancangan Alat}

Setelah melakukan pengujian dari komponen pada masing-masing alat, selanjutnya melakukan pengujian alat secara keseluruhan yang berupa input, proses dan output yang digabungkan secara keseluruhan sehingga menjadi kesatuan alat papan informasi running text dengan pengontrolan menggunakan perangkat android via bluetooth.

Berikut Gambar 6 yang menunjukkan keseluruhan dari rancangan alat yaitu papan informasi dsiplay yang menampilkan running text, suhu, hari, jam, bulan dan tahun.

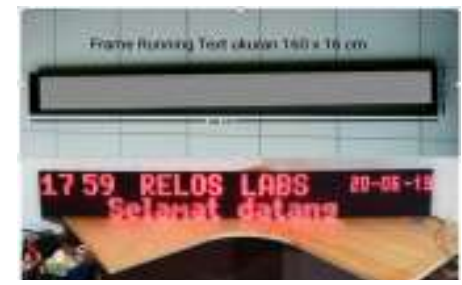

Gambar 6 Rancangan keseluruhan alat

\section{B. Hasil Rancangan Aplikasi}

Secara detail, perancangan aplikasi aplikasi android menggunakan app inventor diuraikan berikut.

Tampilan desain aplikasi running text controller menggunakan app inventor seperti diperlihatkan pada gambar 7.

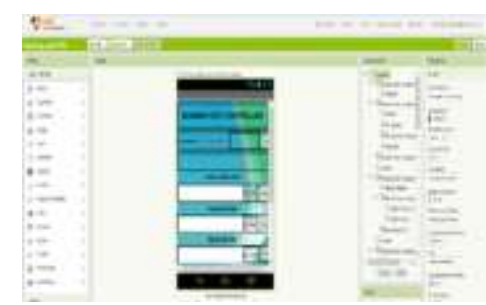

Gambar 7 Desain Aplikasi Android

- Block untuk bluetooth connected dan mengecek bluetooth yang sedang aktif seperti diperlihatkan pada gambar 8.

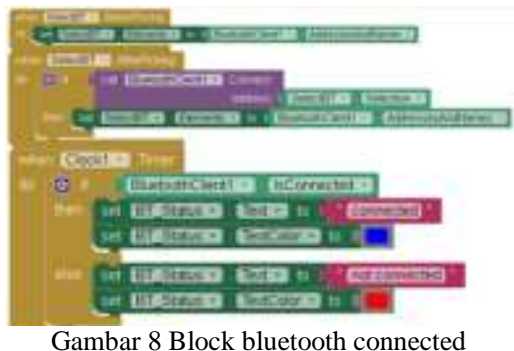

- Tampilan block untuk mengirim center static text dengan penanda tx1 kemudian disortir oleh program pada arduino yang akan tampil pada running text seperti diperlihatkan pada gambar 9 .

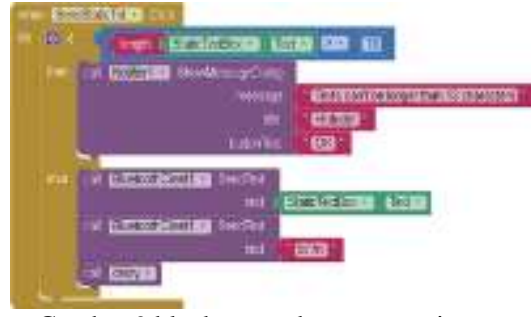

Gambar 9 block penanda center static text

- Block untuk mengirim tiny scroll text dengan penanda tx2 kemudian disortir oleh program pada arduino yang akan tampil pada running text seperti diperlihatkan pada gambar 10

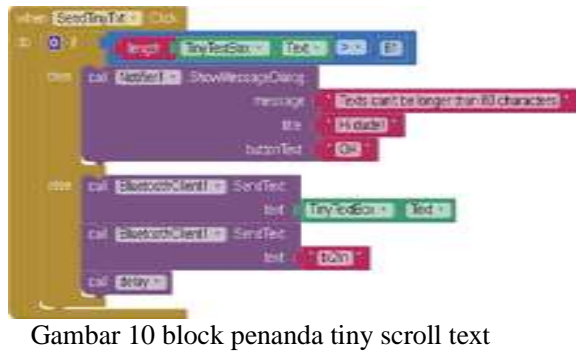

- Tampilan block untuk mengirim big scroll text dengan penanda tx3 kemudian disortir oleh program pada arduino yang akan tampil pada running text seperti diperlihatkan pada gambar 11 ..

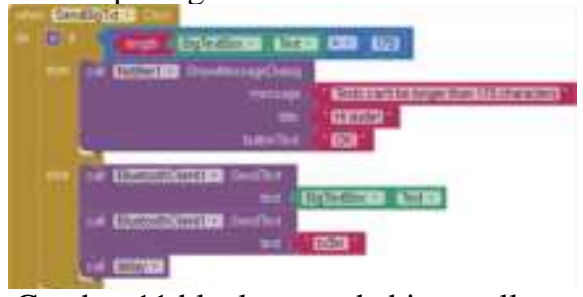

Gambar 11 block penanda big scroll text

- Block untuk mengirim dan mengubah waktu dengan penanda CLK (clock) kemudian disortir oleh program pada arduino yang akan tampil pada display running text seperti diperlihatkan pada gambar 12 .

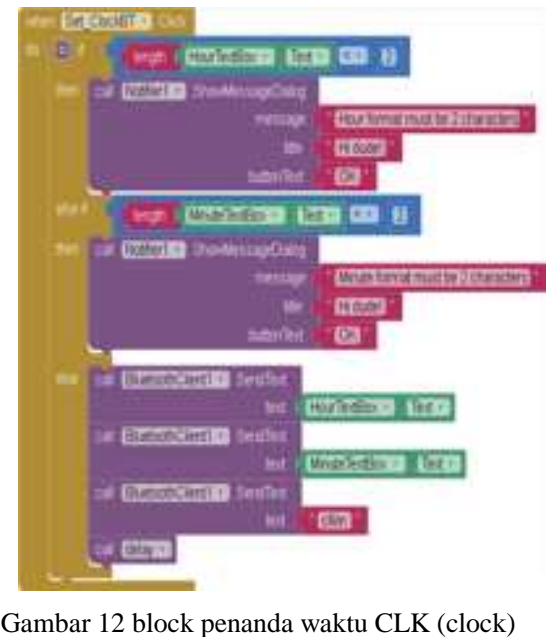

- Tampilan block untuk mengirim dan mengubah tanggal dengan penanda DTE (date) kemudian disortir oleh program pada arduino yang akan tampil pada display running text seperti diperlihatkan pada gambar 13 . 


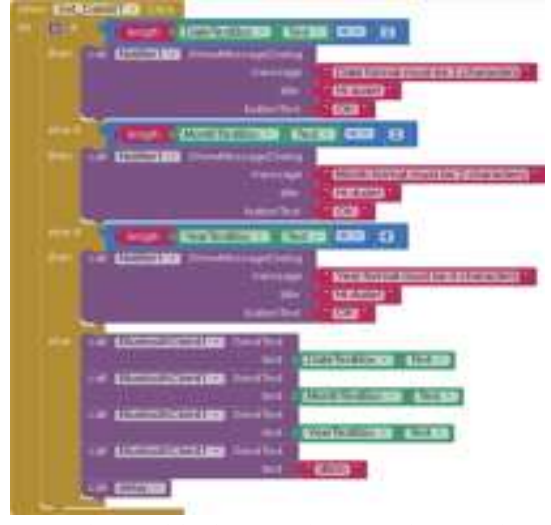

Gambar 13 block penanda tanggal DTE (date)

\section{Hasil Pengujian Alat}

Setelah melakukan pengujian dari komponen pada masing-masing alat, selanjutnya melakukan pengujian alat secara keseluruhan berupa input, proses dan output yang digabungkan secara keseluruhan sehingga menjadi kesatuan alat pengontrol katup air bedasarkan tingkat kekeruhan air.

Pengujian aplikasi android dan alat ditujukan untuk mengetahui apakah proses update running text melalui aplikasi via bluetooth telah terkoneksi dengan baik.

Tampilan aplikasi android untuk mengontrol running text pada panel LED matrix p10 menggunakan bluetooth diperlihatkan pada Gambar 14 berikut :

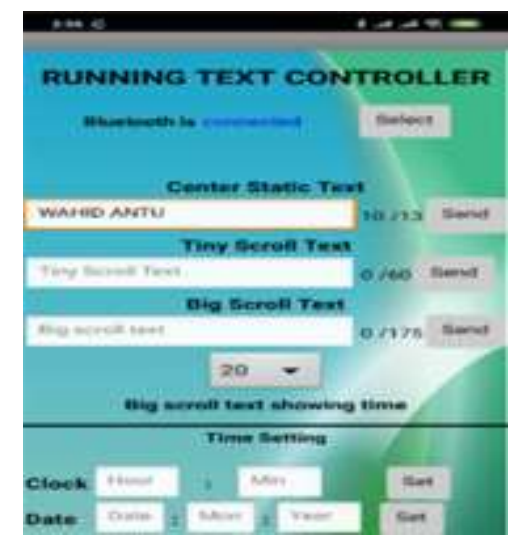

Gambar 14 Tampilan awal aplikasi android

Selanjutnya Tampilan aplikasi android untuk mengkoneksikan bluetooth dari smartphone android ke bluetooth pada panel LED matrix p10 diperlihatkan pada Gambar 15 berikut :

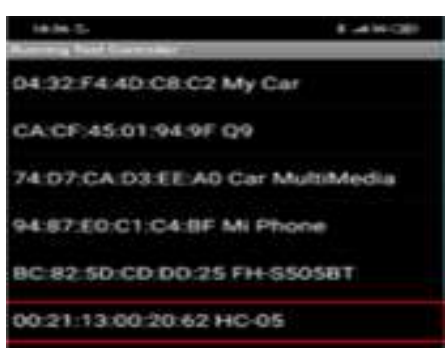

Gambar 15 Tampilan Pencarian Bluetooth Yang Sedang Binding

Tampilan aplikasi android setelah terkoneksi ke bluetooth pada panel LED matrix p10 serta untuk mengupdate data running text center static dari smartphone android ke bluetooth pada panel LED matrix p10 diperlihatkan pada Gambar 16.

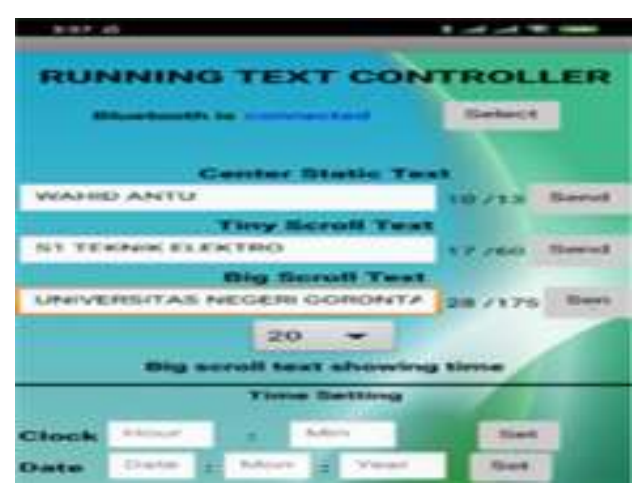

Gambar 16 Bluetooth Terkoneksi Dan Update Text Center Static Text

Hasil upload dari smartphone dengan aplikasi android pada tab center static text setelah terkoneksi ke bluetooth pada panel LED matrix p10 diperlihatkan pada Gambar 17.

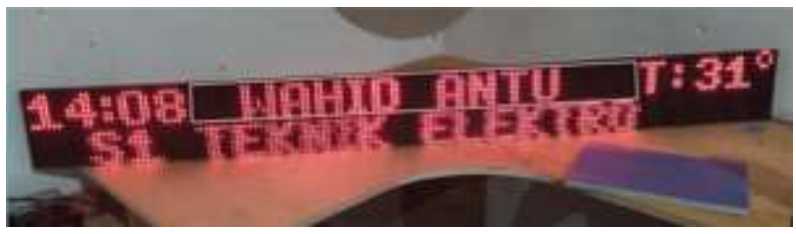

Gambar 17 Tampilan Running Text Setelah Update Text Center Static Text

Tampilan aplikasi android untuk mengupdate data running text Tiny scroll text dari smartphone android ke bluetooth pada panel LED matrix p10 diperlihatkan pada Gambar 18 .

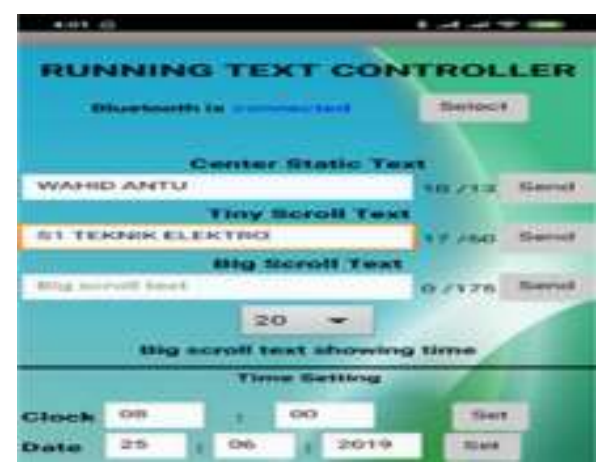

Gambar 18 Tampilan Update Text Tiny Scroll Text

Hasil upload dari aplikasi android pada tab tiny scroll text setelah terkoneksi ke bluetooth pada panel LED p10 diperlihatkan pada Gambar 19.

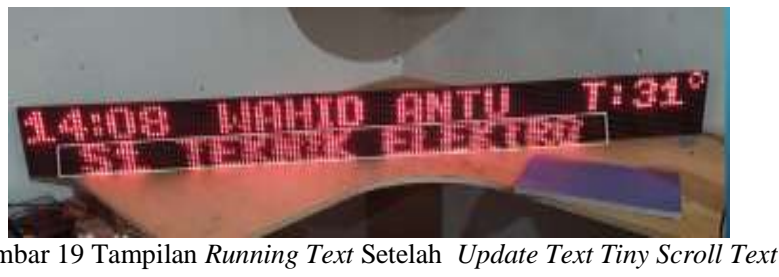

Tampilan aplikasi android untuk mengupdate data running text big scroll text dari smartphone android ke 
bluetooth pada panel LED matrix p10 diperilhatkan pada Gambar 20.

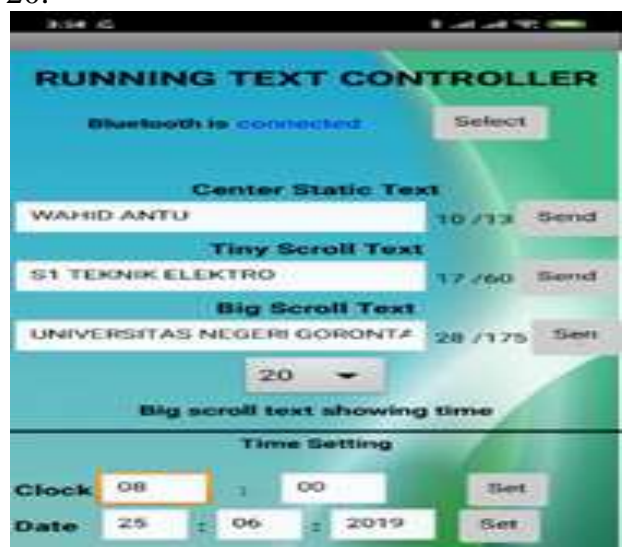

Gambar 20 Tampilan Update Text Big Scroll Text

Hasil upload dari smartphone dengan aplikasi android pada tab big scroll text setelah terkoneksi ke bluetooth pada panel LED matrix p10 diperlihatkan pada Gambar 21.

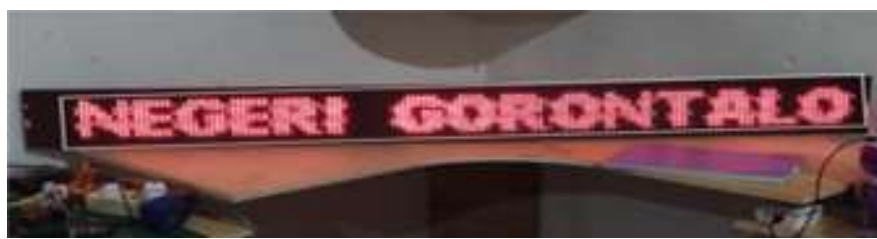

Gambar 21 Tampilan Running Text Setelah Update Text Big Scroll Text

Tampilan aplikasi android untuk mengupdate data waktu dan tanggal dari smartphone android ke bluetooth pada panel LED matrix p10 diperlihatkan pada Gambar 22.

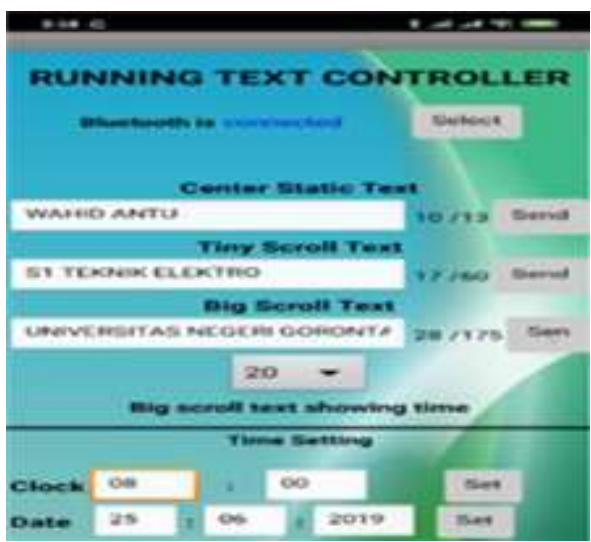

Gambar 22 Tampilan Update Waktu Dan Tanggal

Hasil upload dari smartphone dengan aplikasi android pada tab waktu dan tanggal setelah terkoneksi ke bluetooth pada panel LED matrix p10 diperlihatkan pada Gambar 23.

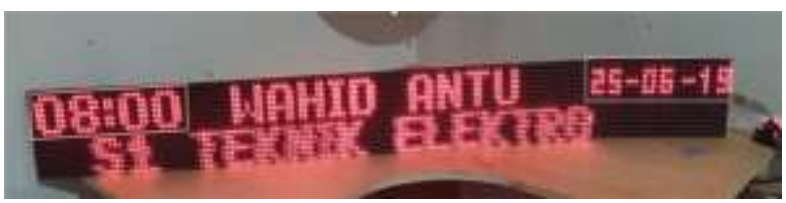

Gambar 23 Tampilan Update Waktu Dan Tanggal

\section{Pengujian sistim}

Setelah melakukan pengujian dari komponen pada masing-masing alat, selanjutnya melakukan pengujian alat secara keseluruhan yang berupa input, proses dan output yang digabungkan secara keseluruhan sehingga menjadi kesatuan alat running text dot matrix P10 16x160 berbasis arduino uno dengan sistim update data menggunakan perangkat android via bluetooth. Pada saat alat mulai dihidupkan, tampilan awal yang akan muncul pada panel LED matrix p10 16x160 adalah tampilan jam, tanggal, tempratur, running text center, running text tiny test dan big scrolling text. Berikut Gambar 24 yang menunjukkan keseluruhan dari rancangan alat.

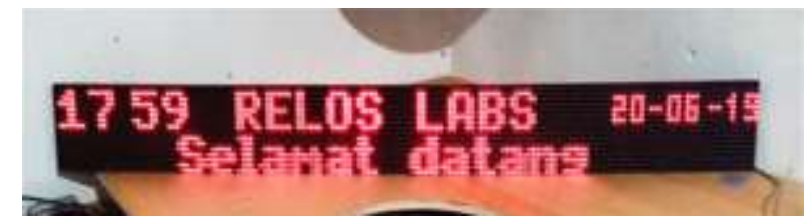

Gambar 24 Tampilan Keseluruhan Rancangan Alat

\section{E. Pengukuran Jarak Maksimal Koneksi Bluetooth}

Seperti yang diketahui, setiap konektivitas bluetooth yang saling terhubung mempunyai batas jarak maksimum untuk saling bertukar data secara real time. Berdasar hal dimaksud, jarak maksimum koneksi bluetoooth kemudian diuji dan hasilnya diberikan pada tabel 1 .

Tabel 1. Pengujian jarak koneksi 12luetooth untuk Update running text

\begin{tabular}{|c|c|c|c|}
\hline No & $\begin{array}{c}\text { Jarak pengiriman } \\
\text { (meter) }\end{array}$ & $\begin{array}{c}\text { Status } \\
\text { koneksi }\end{array}$ & $\begin{array}{c}\text { Waktu Update } \\
\text { (real time) }\end{array}$ \\
\hline 1. & $<=15$ & Connected & 1 detik \\
\hline 2 & $>15$ & $\begin{array}{c}\text { Not } \\
\text { Connected }\end{array}$ & - \\
\hline
\end{tabular}

Dari hasil pengujian koneksi bluetooth dengan panel led p10 seperti tabel 1 diperoleh bahwa koneksi akan tersambung apabila jarak pengiriman data update running text berkisar diantara \pm 1 meter sampai $15 \mathrm{M}$. Sedangkan koneksi akan terputus jika jarak pengiriman data update running text berjarak mulai dari $\pm 16 \mathrm{M}$ dan seterusnya.

Respon waktu bluetooth pada alat yang dikirim melalui bluetooth pada smartphone android yaitu 1 detik ketika update data running text, artinya respon waktu yang diterima bluetooth pada alat, direspon secara real time dari jarak 1 meter sampai 15 meter selama koneksi bluetooth pada smartphone android dengan bluetooth pada alat panel LED p10 masih terhubung.

Kemudian sensor suhu yang mendeteksi tempratur ruangan akan tampil sesuai data yang dibaca oleh sensor dan akan ditampilkan pada panel LED p10.

Untuk pengaturan waktu dan tanggal disetting melalui aplikasi android yang terhubung bluetooth dengan alat panel LED p10, akan ditampilkan bersamaan dengan center text, tiny scrolling text dan suhu pada panel LED p10 sesuai waktu yang disetting dan diupdate melalui aplikasi android.

Berdasarkan keseluruhan proses pengujian yang telah dilakukan, dapat disimpulkan bahwa sistem yang dibangun telah berfungsi dengan baik. 


\section{F. Pembahasan}

Berdasarkan hasil pengujian alat dan sistem secara keseluruhan diperoleh rancang bangun teks pada dot matrix $16 \times 160$ berbasis arduino uno dengan update data system menggunakan perangkat android via bluetooth dapat direalisasikan dengan hasil yang memuaskan, untuk menampilkan informasi berupa teks berjalan yang dapat menampilkan teks berjalan, suhu ruangan serta jam digital yang semua sistemnya dapat di update dengan bluetooth.

Pengujian koneksi bluetooth terhadap respon sistem diperoleh bahwa bahwa koneksi akan tersambung apabila jarak pengiriman data update running text berkisar diantara \pm 1 meter sampai $15 \mathrm{M}$. Sedangkan koneksi akan terputus jika jarak pengiriman data update running text berjarak mulai dari $\pm 16 \mathrm{M}$ dan seterusnya.

Respon waktu bluetooth pada alat yang dikirim melalui bluetooth pada smartphone android yaitu 1 detik ketika update data running text, artinya respon waktu yang diterima bluetooth pada alat, direspon secara real time dari jarak 1 meter sampai 15 meter selama koneksi bluetooth pada smartphone android dengan bluetooth pada alat panel LED p10 masih terhubung.

\section{KESIMPULAN DAN SARAN}

\section{A. Kesimpulan}

Rancangan model alat running text dot matrix $\mathrm{P} 10$ 16x160 berbasis arduino uno dengan update data system menggunakan perangkat android via bluetooth telah direalisasikan sesuai dengan tujuan yaitu merancang aplikasi android update data running text pada panel LED matrix p10 melalui perangkat smartphone dengan aplikasi via bluetooth dimana tampilan running text pada display dapat di update melalui aplikasi android yang terkoneksi dengan bluetooth.

Hasil rancangan alat menggunakan mekanisme konektivitas bluetooth pada aplikasi diperangkat smartphone dengan bluetooth panel LED matrix p10 yang tampil pada display dot matrix p10. Dari percobaan yang telah dilakukan diperoleh hasil bahwa sistem dapat bekerja dengan baik sesuai tujuan.

\section{B. Saran}

Dalam penelitian yang telah dilakukan ini, terdapat saran yang kiranya dapat bermanfaat yaitu : alat pengontrol ini dalam pengiriman data running text masih dalam koneksi bluetooth, maka dapat dikembangkan dengan update data system running text pada panel LED matrix p10 melalui perangkat smartphone dengan aplikasi menggunakan sistim update data jarak jauh misalnya menggunakan IOT (internet of things).

\section{REFERENSI}

[1] Arduino. (2018). Arduino Uno. Retrieved April 18, 2018, from https://store.arduino.cc/arduino-uno-rev3

[2] Fransiscus, Harianto, S. T. R. (2016). Rancang Bangun Alat Pembatas Arus Listrik Dan Monitoring Pemakaian Daya Pada Rumah Sewa Berbasis Mikrokontroler
Arduino Uno. Journal of Control and Network Systems, 5(1), 136-143.

[3] Haryanto, D. H., Ridwan, W., Pd, I. Z. N. S., \& Eng, M. (n.d.). Rancang Bangun Model Pengontrol Katup Air Pdam Bone Bolango Berdasarkan Tingkat Kekeruhan Air Menggunakan Arduino Uno.

[4] Irvan, M. (2019). Rancang Bangun Pengatur Suhu dan Kelembaban Ruang Server Berbasis IoT. palembang.

[5] Kanoi, Yusuf., Abdussamad, Syahrir., Dali. S. W. (2018). Perancangan Jam Digital Waktu Sholat Menggunakan Arduino Uno. https://doi.org/10.1360/zd2013-43-6-1064

[6] Putra, P. S., Rochim, A. F., Widianto, E. D., \& Pratami, M. P. (2014). Alat Pembangkit Suara Ultrasonik Otomatis untuk Merangsang Pembukaan Stomata Tanaman Menggunakan Mikrokontroler ATMega328P Yang Dilengkapi Dengan Panel Surya. Jurnal Teknologi Dan Sistem Komputer, 2(4),288 297. https://doi.org/10.14710/JTSISKOM.2.4.2014.288 $-297$

[7] Rumimper, R. (2016). Rancang Bangun Alat Pengontrol Lampu Dengan Bluetooth Berbasis Android. Teknik Elektro Dan Komputer, 5(3), 24-33.

[8] Simanjuntak, I. U. V, \& Suhendar, A. (2018). Rancang Bangun Running Text P10 16x32 Berbasis Arduino Uno Dengan Komunikasi SMS ( Short Message Service ), IV(2), 116-124.

[9] Syahwill, M. (2013). Panduan Mudah Simulasi Dan Praktek Mikrokontroler Arduino. (T. A. Prabawati, Ed.). Yogyakarta. 